\title{
Review Article \\ Challenges in the Therapy of Visceral Leishmaniasis in Brazil: A Public Health Perspective
}

\author{
Edson Carvalho de Melo ${ }^{1,2}$ and Carlos Magno Castelo Branco Fortaleza ${ }^{2}$ \\ ${ }^{1}$ Hospital Estadual Bauru, Secretaria de Estado da Saúde de São Paulo, 17033-360 Bauru, SP, Brazil \\ ${ }^{2}$ Departamento de Doenças Tropicais e Diagnóstico por Imagem, Faculdade de Medicina de Botucatu, \\ Universidade Estadual Paulista (UNESP), 18618-970 Botucatu, SP, Brazil \\ Correspondence should be addressed to Carlos Magno Castelo Branco Fortaleza; cmfortaleza@uol.com.br
}

Received 27 May 2013; Revised 4 November 2013; Accepted 4 November 2013

Academic Editor: Shyam Sundar

Copyright (C) 2013 E. C. de Melo and C. M. C. B. Fortaleza. This is an open access article distributed under the Creative Commons Attribution License, which permits unrestricted use, distribution, and reproduction in any medium, provided the original work is properly cited.

Over 3,000 yearly cases of Visceral Leishmaniasis (VL) are reported in Brazil. Brazilian Public Health System provides universal free access to antileishmania therapeutic options: Meglumine Antimoniate, Amphotericin B deoxycholate, and Liposomal Amphotericin B. Even though Amphotericin formulations have been advised for severe disease, this recommendation is mostly based on the opinion of experts and on analogy with studies conducted in other countries. Presently, there are two ongoing multicenter clinical trials comparing the efficacy and safety of the available therapeutic options. Some other issues require further clarification, such as severity markers and the approach to VL/AIDS coinfection. Brazil is facing the challenge of providing access to diagnosis and adequate treatment, in order to avoid VL-related deaths.

\section{Introduction}

In the second decade of the 21st century, visceral leishmaniasis (VL) continues to challenge public health authorities around the world. The World Health Organization (WHO) estimates yearly incidence of 500,000 cases, with a casefatality ratio of approximately $10 \%[1,2]$. This picture is especially worrisome for the six countries that harbor $90 \%$ of VL cases: India, Bangladesh, Sudan, South Sudan, Ethiopia, and Brazil $[1,3]$.

Leishmania infantum chagasi is the agent of VL in Latin America. At least twelve Countries in the continent reported VL cases in the past decade. Brazil is by far the most affected country, with more than 3,000 reported cases per year and case-fatality ratio of $5.8 \%$ in the period from 2005 through 2009 [4].

Brazilian picture is worsened by the progressive territorial expansion and urbanization of LV. Up to the early 1980s, the disease was mainly restricted to rural areas in Northeastern Brazil [5]. In the turn of that decade, urban foci of VL were reported in major cities in that region. A southward expansion was also noticed, and the proportion of cases reported outside northeast region increased from 15\% in 1998 to $44 \%$ in 2005 [6].

The changing epidemiology of visceral leishmaniasis posed new challenges for health protection of the residents of the affected areas. In the first place, there is the difficulty of prevention. Measures directed to the canine reservoirs (dog culling, vaccination) or to the vector (environmental intervention, insect repellents) are often impractical in large urban centers. Besides, they were not proved to be definitely effective $[7,8]$. Another challenge concerns the management (including therapy) of VL cases. This is a relevant issue, since case-fatality ratio is generally higher in newly affected regions. São Paulo State (located in Southeastern Brazil) is an example. The first cases were reported in the State's western border in 1999. The pooled case-fatality ratio for 1999-2012 was $8.7 \%$, and it was especially higher (11.5\%) in the first five years [9]. Delay in the diagnosis and institution of appropriate therapy is a possible explanation for those data [10]. Both issues concern public health response. 
The purpose of our review is to discuss the therapeutic options for VL in Brazil and public policies to ensure access throughout the country.

\section{Therapeutic Options Available in the Brazilian VL Program}

The universal and free access to health care is predicted in the Brazilian Constitution and is provided through the Unified Health System (SUS, an acronym for the Portuguese "Sistema Único de Saúde"). Presently there are three therapeutic options for VL available in the SUS: Meglumine Antimoniate (Glucantime), Amphotericin B deoxycholate, and Liposomal Amphotericin B (Ambisome).

Pentavalent antimonials (Meglumine antimoniate and Sodium Stibogluconate) were the first-line treatment for VL for many decades. Besides leishmanicidal activity, antimonials have been shown to induce proinflammatory responses (e.g., enhancement of phagocytosis and production of TNFalpha), which may play a role in controlling VL progression [11-13]. Recently, the use of this class was limited in India due to extensive parasite resistance-up to $60 \%$ [14]. However, there is no evidence of significant resistance to Meglumine Antimoniate in Brazil. On the contrary, reports from observational studies point out to high efficacy. A recent study focusing on a cohort of children treated with antimonials reported efficacy of $96 \%$ in mild-to-moderate cases, and over $60 \%$ in severe cases [15]. The same study found rates above $15 \%$ for cardiac, hepatic, and pancreatic toxicity. Toxicity is indeed a major concern, and severe cases (sometimes leading to death) have been reported, mostly in patients above 50 years of age [16]. Moreover, Antimoniates are contraindicated in pregnancy and in patients with renal failure [17]. There is also concern about failures and relapses in special groups, such as those with AIDS-VL coinfection and other immune-suppressed patients [18]. The recommended dosing regimen for Glucantime is $20 \mathrm{mg} / \mathrm{kg} /$ day of Antimoniate (up to $1215 \mathrm{mg}$ /day, which represent three vials), for 20-40 days.

Amphotericin $B$ deoxycholate $(A B D)$ was introduced as second-line therapy for VL in the 1960s. This drug has excellent leishmanicidal activity, with cure rates of $90 \%-95 \%$ in studies from endemic countries [19]. Similar to antimonials, $\mathrm{ABD}$ (as well as lipid formulations) was also shown to have immune modulatory effects, including regulation of T-cell proliferation and enhancement of pro-inflammatory cytokines production [20-22].

There are, however, significant obstacles to the widespread use of this drug. The administration must be slow in order to avoid infusion-related adverse effects. This fact makes the treatment in an inpatient or day-hospital scheme necessary. Furthermore, the nephrotoxicity rates may be higher than 50\% [23]. Until 2013, Brazilian guidelines for treatment of severe VL recommended the choice of Amphotericin B deoxycholate for patients in extremes of age (over 65 years or under 6 months), with signs of malnourishment or significant comorbidities. The recommended posology is $1 \mathrm{mg} / \mathrm{Kg} /$ day (maximum $50 \mathrm{mg} /$ day) for $14-21$ days [24]. A recent document from Brazilian Health Ministry
(September 2013) updated that recommendation [25]. In the revised guidelines, the groups cited above should be preferably treated with Liposomal Amphotericin.

The lipid formulations of Amphotericin B greatly increased the safety in the therapy of systemic mycosis and VL [26]. Presently there are three formulations in the market: Amphotericin lipid complex (Abelcet), Amphotericin colloidal dispersion (Amphocil), and Liposomal Amphotericin (AmBisome). Though they are not bioequivalent (and probably not therapeutically equivalent), all of them allow the administration of doses above $5 \mathrm{mg} / \mathrm{kg} /$ day. Current data suggest that liposomal amphotericin is less toxic [26]. This formulation is also the only one that has been extensively studied in the therapy of VL [27].

Several dosing schemes of Liposomal Amphotericin have been studied for VL in different countries, ranging from single doses of $10 \mathrm{mg} / \mathrm{kg}$ [28] to a total of $18-21 \mathrm{mg} / \mathrm{kg} /$ day distributed over 5-7 days (i.e., 3-5 mg/kg/day) [29]. The reported efficacy is generally above $90 \%$ [30].

In Brazil, recommended doses are 3-4 mg/kg/day for 5-7 days (Ministry of Health) $[18,24,25]$ and 3-5 mg/kg/day for 5 days (São Paulo State Health Department) [31].

The major limitation for the use of Liposomal Amphotericin is its price, and this fact has weighed negatively on cost-effectiveness analysis [32]. However, this has been overcome by an agreement with the producing industry (Gilead), which allowed Brazilian Health Ministry to purchase AmBisome at prices much lower than those prevailing in the market.

\section{Therapeutic Challenges: Severe Patients and AIDS Coinfection}

The Brazilian Health Ministry recommendations for severe VL favor the use of liposomal Amphotericin B. The evidence for this choice is not strong. It is based on the opinion of experts and on analogy from clinical trials mostly conducted in India [33]. While the urgent need for reducing case-fatality rates justifies decisions based on incomplete evidence, some major questions remain. What is the definition of "severe VL"? Which are the clinical signs and laboratory markers of severity?

Four recent studies focusing on predictors of death in VL patients showed agreement in most findings [10, 34-36]. Briefly, delay in the diagnosis, age above 60 years, hemorrhagic manifestations, jaundice, suspected or confirmed bacterial infection, neutropenia, low platelet counts, and AIDS coinfection were associated with worse outcomes. All those factors, alongside with anemia, renal failure, malnourishment, and low serum albumin $(<2.5 \mathrm{mg} / \mathrm{dL})$, are listed as severity markers in the most recent governmental recommendations for treatment of severe VL [24, 25]. Although this document does not indicate unequivocally the use of amphotericin B (deoxycholate or liposomal) for patients in this condition, it determines the availability and logistics to supply these drugs throughout the country. Given the country continental extent and the disparities in social/economic development among regions-which have an impact on 
patients access to health services-this commitment is of foremost importance.

AIDS/VL coinfection is also an important issue in Brazil. Trends in VL reemergence (urbanization) and AIDS epidemiology (interiorization, i.e., progress towards cities in inner Brazil) made covered areas of the two diseases intertwine [37]. Thus, similar to what had happened in Europe and Africa [38], co-infection became epidemiologically and clinically relevant. In 2007-2008, approximately $4 \%$ of VL cases in Brazil were coinfections [39]. This proportion varied among States and reached nearly 10\% in São Paulo.

A comprehensive account of specificities of AIDS/VL co-infection is beyond the objectives of this review. Still, some of the major challenges are worth citing: (a) atypical and severe presentations, which hinder diagnosis and impact unfavorably on outcomes [40, 41]; (b) failure of therapy with antimonials [18]; and (c) frequent relapses and the need for long-term suppressive therapy [42]. Given the unfavorable outcomes of co-infected patients, Brazilian Health Ministry revised therapeutic guidelines in year 2013, including HIV co-infection as an indication for therapy with Liposomal Amphotericin.

The beneficial effect of highly active antiretroviral therapy (HAART) in the prevention of symptomatic VL or of relapses is still not clear, both in Brazil or in a worldwide perspective [42]. This is an important issue, since patients with VL/AIDS co-infection may benefit from the universal access to antiretrovirals provided by the Brazilian Aids Program [43].

\section{The São Paulo State Experience}

At this point, making a brief description of the governmental approach of VL therapy in the State of São Paulo is worth. This is the most populous and economically developed among the 26 states in Brazil. As discussed earlier, the first autochthonous case of VL was reported in 1999. In the first five years, pooled case-fatality ratio was $11.5 \%$-about two times the value for Brazil. In an effort to lower death rates, the State expedited guidelines in 2006, recommending therapy with Liposomal Amphotericin for all children up to 10 years of age and adults over 50 years. VL/AIDS co-infection, pregnancy, and relapses were also defined as indications for Liposomal Amphotericin [31]. Those recommendations were considerably wider than those proposed by the Brazilian Health Ministry at that time [17]. In years that followed the expedition of the State Guideline (2006-2012), the casefatality ratio was $7.8 \%(\mathrm{RR}=0.67 ; 95 \% \mathrm{CI}, 0.50-0.91, P=$ 0.01 ). Of course, many issues may account for this finding (including improvement in diagnosis and access to health system). Still, a more refined analysis of the Database for Notifiable Diseases may throw some light on the possible beneficial effect of the change in São Paulo State therapeutic recommendations.

\section{Difficulties and Future Prospects}

Some of the challenges for the treatment of visceral leishmaniasis in Brazil are generic. They relate to the difficulties of providing free health care throughout the territory of a huge developing country. It is worth remembering that, especially in the Amazon Region, VL patients may have difficulty in transportation to centers where treatment is available. In this sense, the Public Health System has sought empowerment of regional centers for the care of VL cases.

Other challenges are more specific. Little is known about the effectiveness of treatment options available in SUS. We emphasized previously how much the current recommendations are based on expert opinion and the analogy with clinical trials that focused on Indian or African VL. Here, too, the Ministry of Health of Brazil has undertaken significant effort. Through its department of science and technology (DECIT) and the Brazilian Innovation Agency (FINEP), two multicenter clinical trials were funded, with the aim of comparing the efficacy and safety of the available therapeutic options. One of those trials is also assessing combination therapy with different drugs, a strategy that proved useful in other countries $[29,44]$. When available, data from those trials will provide valuable data to guide definite governmental recommendations.

Since the effect of preventive strategies is not established [8], timely diagnosis and adequate therapy may be the most important goals to avoid VL-related deaths. The development and validation of a unified severity score could help in guiding therapeutic choice. A thorough approach to data from Epidemiologic Surveillance Files may also be of help in providing information on the effectiveness of VL therapy in a "real-life" setting. Those are important issues for research. While many questions remain on the efficacy and cost-effectiveness of VL therapeutic options in Brazil, it is certain that the country is making great progress toward an evidence-based approach to this potentially life-threatening disease.

\section{References}

[1] World Health Orgazination, "Leishmaniasis: epidemiology and access to medicines-an update based on the outcomes of WHO regional meetings, literature review and experts' opinion, Geneve (WHO)," 2012, http://www.who.int/leishmaniasis/resources/Leishmaniasis_worldwide_epidemiological_and_drug_ access_update.pdf.

[2] F. Chappuis, S. Sundar, A. Hailu et al., "Visceral leishmaniasis: what are the needs for diagnosis, treatment and control?" Nature Reviews Microbiology, vol. 5, no. 11, pp. 873-882, 2007.

[3] J. Alvar J, I. D. Vélez, C. Bern C et al., "Leishmaniasis worldwide and global estimates of its incidence," PLoS One, vol. 7, no. 5, Article ID e35671, 2012.

[4] D. M. Pelissari, M. P. Cechinel, M. L. Souza-Gomes, and F. E. Lima Junior, "Tratamento da leishmaniose visceral e tegumentar americana no Brasil," Epidemiologia e Serviços de Saúde, vol. 20, no. 1, pp. 107-110, 2011.

[5] A. N. S. Maia-Elkhoury, W. A. Alves, M. L. De Sousa-Gomes, J. M. De Sena, and E. A. Luna, "Visceral leishmaniasis in Brazil: trends and challenges," Cadernos de Saúde Publica, vol. 24, no. 12, pp. 2941-2947, 2008.

[6] M. O. Harhay, P. L. Olliaro, D. L. Costa, and C. H. N. Costa, "Urban parasitology: visceral leishmaniasis in Brazil," Trends in Parasitology, vol. 27, no. 9, pp. 403-409, 2011. 
[7] C. H. Costa, C. M. Tapety, and G. L. Werneck, "Controle da leishmaniose visceral em meio urbano: estudo de intervenção randomizado fatorial," Revista da Sociedade Brasileira de Medicina Tropical, vol. 40, no. 4, pp. 415-419, 2007.

[8] G. A. S. Romero and M. Boelaert, "Control of visceral leishmaniasis in latin America-a systematic review," PLoS Neglected Tropical Diseases, vol. 4, no. 1, Article ID e584, 2010.

[9] Centro de vigilância epidemiológica da secretaria de estado da saúde de são paulo, "Leishmaniose visceral Americana: dados estatísticos," 2013, http://www.cve.saude.sp.gov.br/htm/zoo/ leishv_dados.html.

[10] G. Madalosso, C. M. Fortaleza, A. F. Ribeiro, L. L. Cruz, P. A. Nogueira, and J. A. Lindoso, "American visceral leishmaniasis: factors associated with lethality in the state of são paulo, Brazil," Journal of Tropical Medicine, vol. 2012, Article ID 281572, 7 pages, 2012.

[11] A. Kocyigit, S. Gur, M. S. Gurel, V. Bulut, and M. Ulukanligil, "Antimonial therapy induces circulating proinflammatory cytokines in patients with cutaneous leishmaniasis," Infection and Immunity, vol. 70, no. 12, pp. 6589-6591, 2002.

[12] M. I. Muniz-Junqueira and V. N. de Paula-Coelho, "Meglumine antimonate directly increases phagocytosis, superoxide anion and TNF- $\alpha$ production, but only via TNF- $\alpha$ it indirectly increases nitric oxide production by phagocytes of healthy individuals, in vitro," International Immunopharmacology, vol. 8, no. 12, pp. 1633-1638, 2008.

[13] R. R. de Saldanha, M. C. Martins-Papa, R. N. Sampaio, and M. I. Muniz-Junqueira, "Meglumine antimonate treatment enhances phagocytosis and TNF- $\alpha$ production by monocytes in human cutaneous leishmaniasis," Transactions of the Royal Society of Tropical Medicine and Hygiene, vol. 106, no. 10, pp. 596-603, 2012.

[14] S. Mondal, P. Bhattacharya, and N. Ali, "Current diagnosis and treatment of visceral leishmaniasis," Expert Review of AntiInfective Therapy, vol. 8, no. 8, pp. 919-944, 2010.

[15] Y. M. Brustoloni, R. V. Cunha, L. Z. Cônsolo, A. L. L. Oliveira, M. E. C. Dorval, and E. T. Oshiro, "Treatment of visceral leishmaniasis in children in the central-west region of Brazil," Infection, vol. 38, no. 4, pp. 261-267, 2010.

[16] A. L. L. De Oliveira, Y. M. Brustoloni, T. D. Fernandes, M. E. C. Dorval, R. V. Da Cunha, and M. N. Bóia, "Severe adverse reactions to meglumine antimoniate in the treatment of visceral leishmaniasis: a report of 13 cases in the southwestern region of Brazil," Tropical Doctor, vol. 39, no. 3, pp. 180-182, 2009.

[17] Ministério Da Saúde, Secretaria De Vigilância Em Saúde, Manual De Vigilância E Controle Da Leishmaniose Visceral, Departamento De Vigilância Epidemiológica, Brasília, Brazil, 2006.

[18] G. F. Cota, M. R. de Sousa, T. O. Fereguetti, and A. Rabello, "Efficacy of anti-leishmania therapy in visceral leishmaniasis among HIV infected patients: a systematic review with indirect comparison," PLoS Neglected Tropical Diseases, vol. 7, no. 5, Article ID e2195, 2013.

[19] H. W. Murray, "Progress in the treatment of a neglected infectious disease: visceral leishmaniasis," Expert Review of Anti-Infective Therapy, vol. 2, no. 2, pp. 279-292, 2004.

[20] W. R. Cuna, R. Velasquez, J. Riva, I. Guachalla, and C. Rodríguez, "Enhancement of a $\mathrm{T}_{H} 1$ immune response in amphotericin B-treated mucocutaneous leishmaniasis," Journal of Biomedicine and Biotechnology, vol. 2007, Article ID 96410, 4 pages, 2007.
[21] S. Kumar and R. Chakrabarti, "Amphotericin B both inhibits and enhances T-cell proliferation: inhibitory effect is mediated through $\mathrm{H}_{2} \mathrm{O}_{2}$ production via cyclooxygenase pathway by macrophages," Journal of Cellular Biochemistry, vol. 77, no. 3, pp. 361-371, 2000.

[22] T. Ehrenfreund-Kleinman, A. J. Domb, C. L. Jaffe, A. Nasereddin, B. Leshem, and J. Golenser, "The effect of amphotericin B derivatives on Leishmania and immune functions," Journal of Parasitology, vol. 91, no. 1, pp. 158-163, 2005.

[23] S. Sundar and M. Chatterjee, "Visceral leishmaniasis-current therapeutic modalities," Indian Journal of Medical Research, vol. 123, no. 3, pp. 345-352, 2006.

[24] Ministério Da Saúde, Secretaria De Vigilância Em Saúde, Leishmaniose Visceral : RecomenDações Clínicas Para Redução Da letalidade, Departamento De Vigilância Epidemiológica, Brasília, Brazil, 2011.

[25] Ministério Da Saúde, Secretaria De Vigilância Em Saúde, Novo Protocolo de Tratamento Para a Leishmaniose Visceral, Departamento De Vigilância Epidemiológica, Brasília, Brazil, 2013.

[26] C. Cifani, S. Costantino, and M. Massi L Berrino, "Commercially available lipid formulations of amphotericin b: are they bioequivalent and therapeutically equivalent?" Acta Biomedica, vol. 83, no. 2, pp. 154-163, 2012.

[27] A. H. Mohamed-Ahmed, S. Brocchini, and S. L. Croft, "Recent advances in development of amphotericin B formulations for the treatment of visceral leishmaniasis," Current Opinion in Infectous Diseases, vol. 25, no. 6, pp. 695-702, 2012.

[28] S. Sundar, J. Chakravarty, D. Agarwal, M. Rai, and H. W. Murray, "Single-dose liposomal amphotericin B for visceral leishmaniasis in India," The New England Journal of Medicine, vol. 362, no. 6, pp. 504-512, 2010.

[29] S. Sundar and J. Chakravarty, "Leishmaniasis: an update of current pharmacotherapy," Expert Opinion in Pharmacotherapy, vol. 14, no. 1, pp. 53-63, 2013.

[30] M. Balasegaram, K. Ritmeijer, M. A. Lima et al., "Liposomal amphotericin B as a treatment for human leishmaniasis," Expert Opinion on Emerging Drugs, vol. 17, no. 4, pp. 493-510, 2012.

[31] São Paulo (Estado), Secretaria de Estado da Saúde, Superintendência de Controle de Endemias-SUCEN e Coordenadoria de Controle de Doenças, "Manual de Vigilância e Controle da Leishmaniose Visceral Americana do Estado de São Paulo," Secretaria de Saúde, São Paulo, Brazil, 2006.

[32] V. Vanlerberghe, G. Diap, P. J. Guerin et al., "Drug policy for visceral leishmaniasis: a cost-effectiveness analysis," Tropical Medicine and International Health, vol. 12, no. 2, pp. 274-283, 2007.

[33] P. L. Olliaro, P. J. Guerin, S. Gerstl, A. A. Haaskjold, J. A. Rottingen, and S. Sundar, "Treatment options for visceral leishmaniasis: a systematic review of clinical studies done in India, 1980-2004," Lancet Infectious Diseases, vol. 5, no. 12, pp. 763-774, 2005.

[34] G. L. Werneck, M. S. A. Batista, J. R. B. Gomes, D. L. Costa, and C. H. N. Costa, "Prognostic factors for death from visceral leishmaniasis in Teresina, Brazil," Infection, vol. 31, no. 3, pp. 174-177, 2003.

[35] M. J. A. D. Q. Sampaio, N. V. Cavalcanti, J. G. B. Alves, M. J. C. F. Filho, and J. B. Correia, "Risk factors for death in children with visceral leishmaniasis," PLoS Neglected Tropical Diseases, vol. 4, no. 11, Article ID e877, 2010.

[36] V. E. M. de Araújo, M. H. F. Morais, I. A. Reis, A. Rabello, and M. Carneiro, "Early clinical manifestations associated with death 
from visceral leishmaniasis," PLoS Neglected Tropical Diseases, vol. 6, no. 2, Article ID e1511, 2012.

[37] A. Rabello, M. Orsini, and J. Disch, "Leishmania/HIV coinfection in Brazil: an appraisal," Annals of Tropical Medicine and Parasitology, vol. 97, supplement 1, pp. 17-28, 2003.

[38] J. Alvar, P. Aparicio, A. Aseffa et al., "The relationship between leishmaniasis and AIDS: the second 10 years," Clinical Microbiology Reviews, vol. 21, no. 2, pp. 334-359, 2008.

[39] M. L. Souza-Gomes, A. N. Maia-Elkhoury, D. M. Pelissari, F. E. Lima Junior, J. M. Sena, and M. P. Cechinel, "Coinfecção Leishmania-HIV no Brasil: aspectos epidemiológicos, clínicos e laboratoriais," Epidemiologia e Serviços de Saúde, vol. 20, no. 4, pp. 519-526, 2011.

[40] J. N. Jarvis and D. N. Lockwood, "Clinical aspects of visceral leishmaniasis in HIV infection," Current Opinion in Infectious Diseases, vol. 26, no. 1, pp. 1-9, 2013.

[41] E. F. Daher, P. P. Fonseca, E. S. Gerhard, T. M. J. Silva Leitão, and G. B. Silva Júnior, "Clinical and epidemiological features of visceral leishmaniasis and HIV co-infection in fifteen patients from Brazil," Journal of Parasitology, vol. 95, no. 3, pp. 652-655, 2009.

[42] G. F. Cota, M. R. de Sousa, and A. Rabello, "Predictors of visceral leishmaniasis relapse in HIV-infected patients: a systematic review," PLoS Neglected Tropical Diseases, vol. 5, no. 6, Article ID el153, 2011.

[43] P. J. Flaer and M. Z. Younis, “The Brazilian experiment: HIV drugs for all," Journal of Health Care Finance, vol. 36, no. 2, pp. 90-96, 2009.

[44] J. van Griensven, M. Balasegaram, F. Meheus, J. Alvar, L. Lynen, and M. Boelaert, "Combination therapy for visceral leishmaniasis," The Lancet Infectious Diseases, vol. 10, no. 3, pp. 184-194, 2010. 


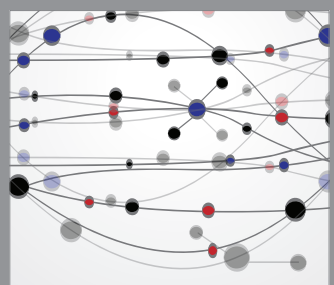

The Scientific World Journal
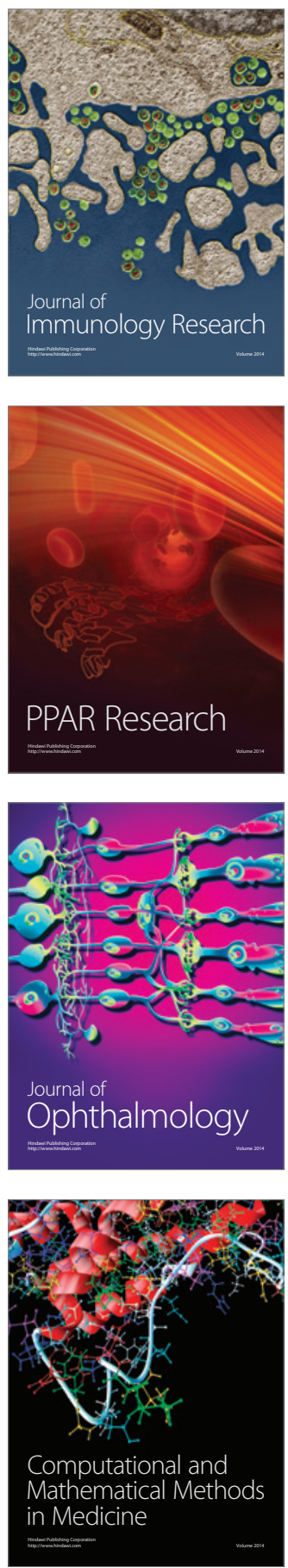

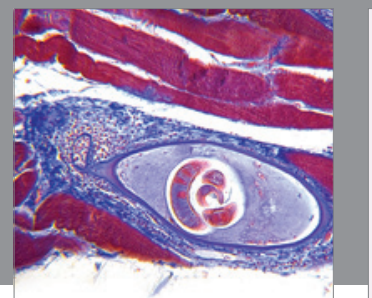

Gastroenterology

Research and Practice
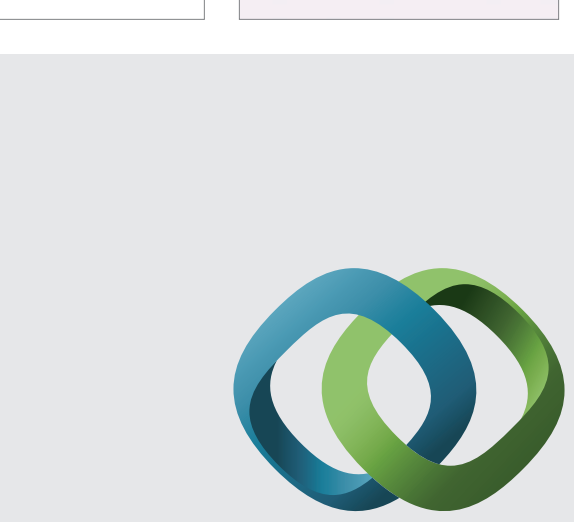

\section{Hindawi}

Submit your manuscripts at

http://www.hindawi.com
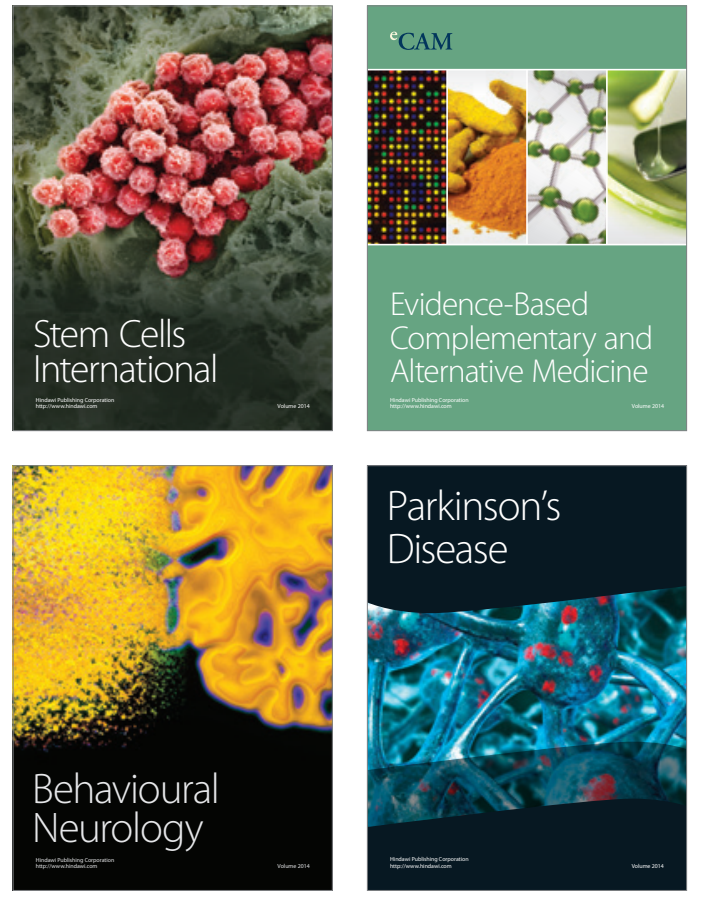
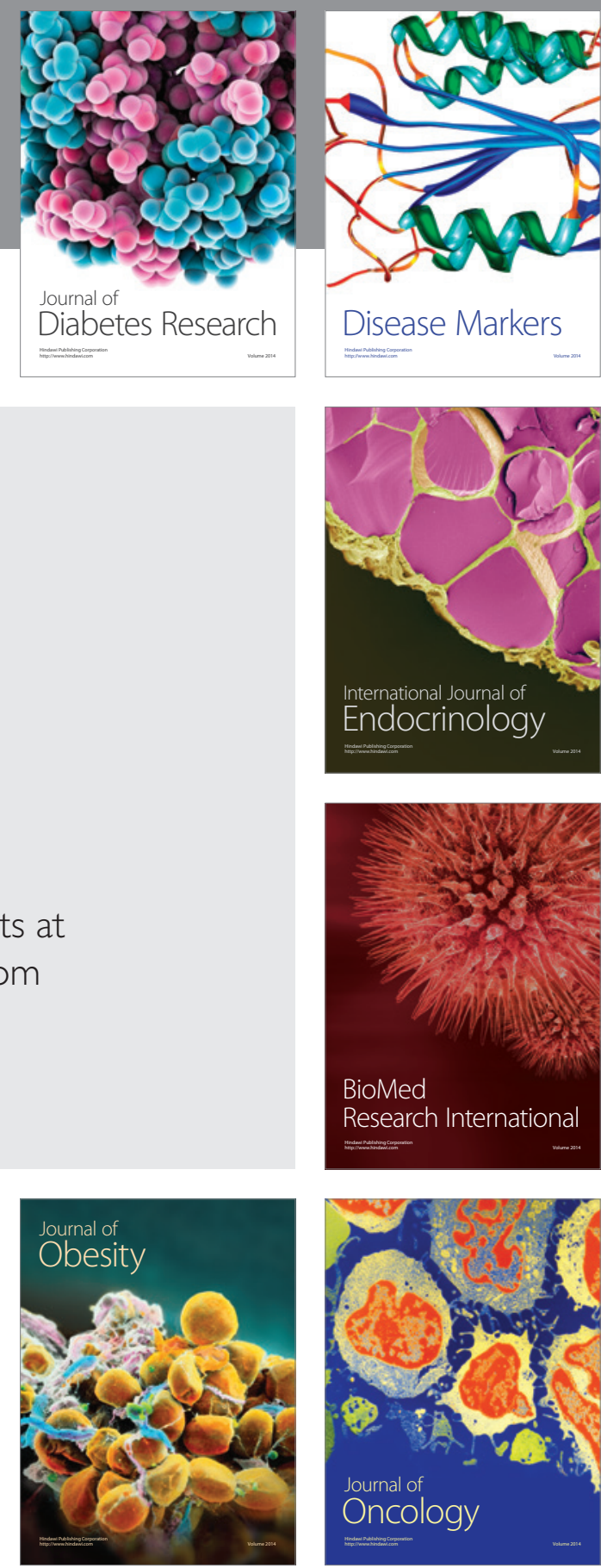

Disease Markers
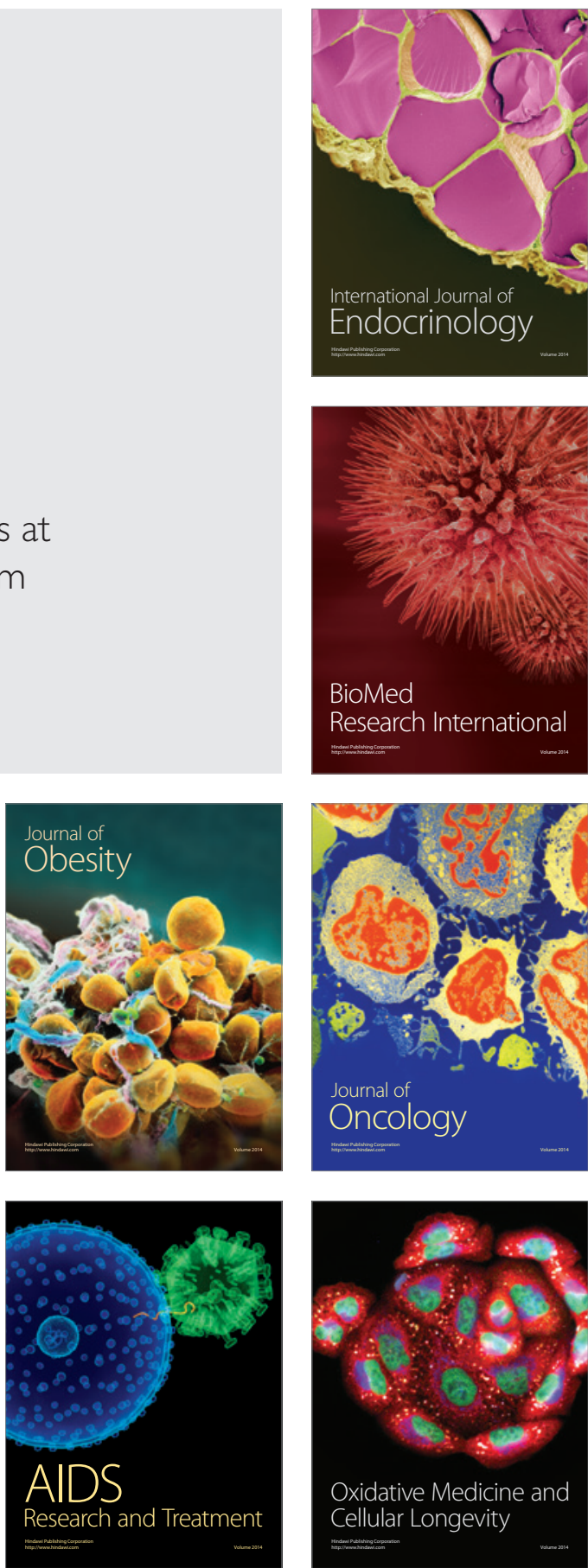